\title{
Fruit and vegetable consumption in relation to risk factors for cancer: a report from the Malmö Diet and Cancer Study
}

\author{
Peter Wallström ${ }^{1, *}$, Elisabet Wirfält ${ }^{1}$, Lars Janzon ${ }^{2}$, Irene Mattisson ${ }^{1}$, Sölve Elmståhl², \\ Ulla Johansson ${ }^{1,3}$ and Göran Berglund ${ }^{1}$ \\ 'Department of Medicine, Lund University, Malmö University Hospital, SE-205 02 Malmö, Sweden: \\ ${ }^{2}$ Department of Community Medicine, Lund University, Malmö University Hospital, SE-205 02 Malmö, Sweden: \\ ${ }^{3}$ Present address: Idun Mat- and Näringskonsult, Blidrädersr. 6E, SE-222 28 Lund, Sweden
}

Submitted 19 December 1999: Accepted 20 March 2000

\begin{abstract}
Objective: To examine the associations between the consumption of fruit and vegetables and other markers of cancer risk.

Design: A cross-sectional survey within the population-based prospective Malmö Diet and Cancer (MDC) Study. Information on food habits was collected through the modified diet history method designed and validated for the MDC Study. Data on smoking and alcohol habits, leisure time physical activity, birth country, education, socioeconomic status and cohabitation status were collected through a questionnaire. Setting: Malmö, the third largest city in Sweden.

Subjects: All subjects who entered the MDC Study during winter 1991 to summer 1994 (men and women living in Malmö, aged between 46 and 68 years), with a total of 15173.

Results: Women consumed more fruit and vegetables than men. Low consumption of both fruits and vegetables was associated with unfavourable nutrient profiles: higher percentage of energy from fat and lower intakes of antioxidant nutrients and dietary fibre. Low consumption was also associated with smoking, low leisure time physical activity, low education and being born in Sweden. High age was associated with low vegetable consumption in both genders. Alcohol intake was positively associated with vegetable consumption in both genders, while both zero and high alcohol consumers had low fruit consumption. Men residing without a partner consumed less fruits and vegetables than other men. There were very weak or no independent associations between socioeconomic status and fruit/vegetable consumption.

Conclusion: This study indicates that several established risk markers and risk factors of cancer may be independently associated with low fruit and vegetable consumption. The findings suggest that the adverse effects of factors such as smoking, low physical activity and a high-fat diet could partly be explained by low consumption of fruit or vegetables. The implied health benefits of a low or moderate alcohol consumption may be similarly confounded by high consumption of fruit or vegetables.
\end{abstract}

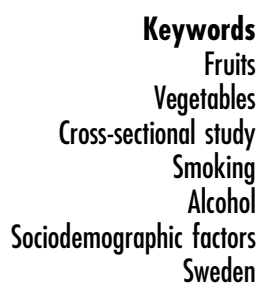

High consumption of fruit and vegetables has, in several epidemiological studies, been associated with reduced cancer risk. This seemingly protective effect may be related to an inhibitory influence of antioxidants on initiation and promotion of cancer ${ }^{1,2}$. Other compounds present in fruit and vegetables (e.g. phase I and II enzyme inducers, inhibitors of cell proliferation and inducers of DNA repair) may exert similar effects ${ }^{3,4}$.

An alternative explanation is that high consumers of fruits and vegetables are less often exposed to other agents and conditions known to be associated with cancer than low consumers. Low intake of energy and fat, absence of exposure to smoking and alcohol, and high physical activity are all potential confounders. Similarly, incidence of cancer varies between socioeconomic groups and geographical areas. To what extent these associations may be explained by exposure to foods and nutrients claimed to be related to cancer, remains controversial.

The objective in this study from the population-based MDC Study cohort has been to describe the consumption of fruits and vegetables in groups defined in terms of education, occupation, ethnical background, cohabitation 
status, smoking, alcohol consumption and physical activity. A second objective has been to briefly describe the associations between consumption of fruits and vegetables and intake of nutritional factors such as energy, macronutrients, dietary fibre and antioxidant micronutrients.

\section{Methods}

\section{Study population}

Malmö is a city in southern Sweden with approximately 240000 inhabitants. At the start of the MDC Study in winter 1991, its source population consisted of all men and women living in Malmö born between 1926 and 1945 $(n=53000)^{5}$. About $16 \%$ of these were born outside of Sweden, mostly persons from eastern Europe and the Balkan countries, Scandinavia and other European countries.

The most important recruitment method in the MDC Study was letters of invitation to individuals chosen at random from the source population. Letters were followed by phone calls, when necessary and possible. Information about the study was also spread through advertisements in local media and through collaboration with major employers in Malmö. This meant that 4761 persons entered the study before receiving a letter of invitation.

In September 1994, the procedures for collecting dietary data in the MDC Study were altered in order to reduce interview time (E. Wirfält et al., submitted). The population chosen for the present study therefore included every person who completed the MDC Study baseline examination from the start of the study in winter 1991 to August $1994(n=17648)$. Excluded were 2475 persons who did not complete the diet survey. This left 15173 persons, of whom 15080 also filled out the MDC Study questionnaire (see below). They are described in Table 1.

\section{Data collection}

The study subjects visited the MDC study centre twice. At the first visit project staff provided groups of subjects with information on the background and aim of the project, and detailed instructions about the lifestyle questionnaire and the dietary data collection procedure. At the second visit individual interviews were conducted to complete the diet history and to check that the lifestyle questionnaire was filled out correctly. The subjects were assigned to interviewers at random.

\section{Dietary assessment}

Food habit information was collected through a modified diet history method, specifically designed for the MDC Study $^{6-8}$. The method combines quantitative and semiquantitative approaches and measures the entire diet, including cooking methods. It consists of two parts: a 'menu book' for description of cooked meals and
Table 1 Study population characteristics

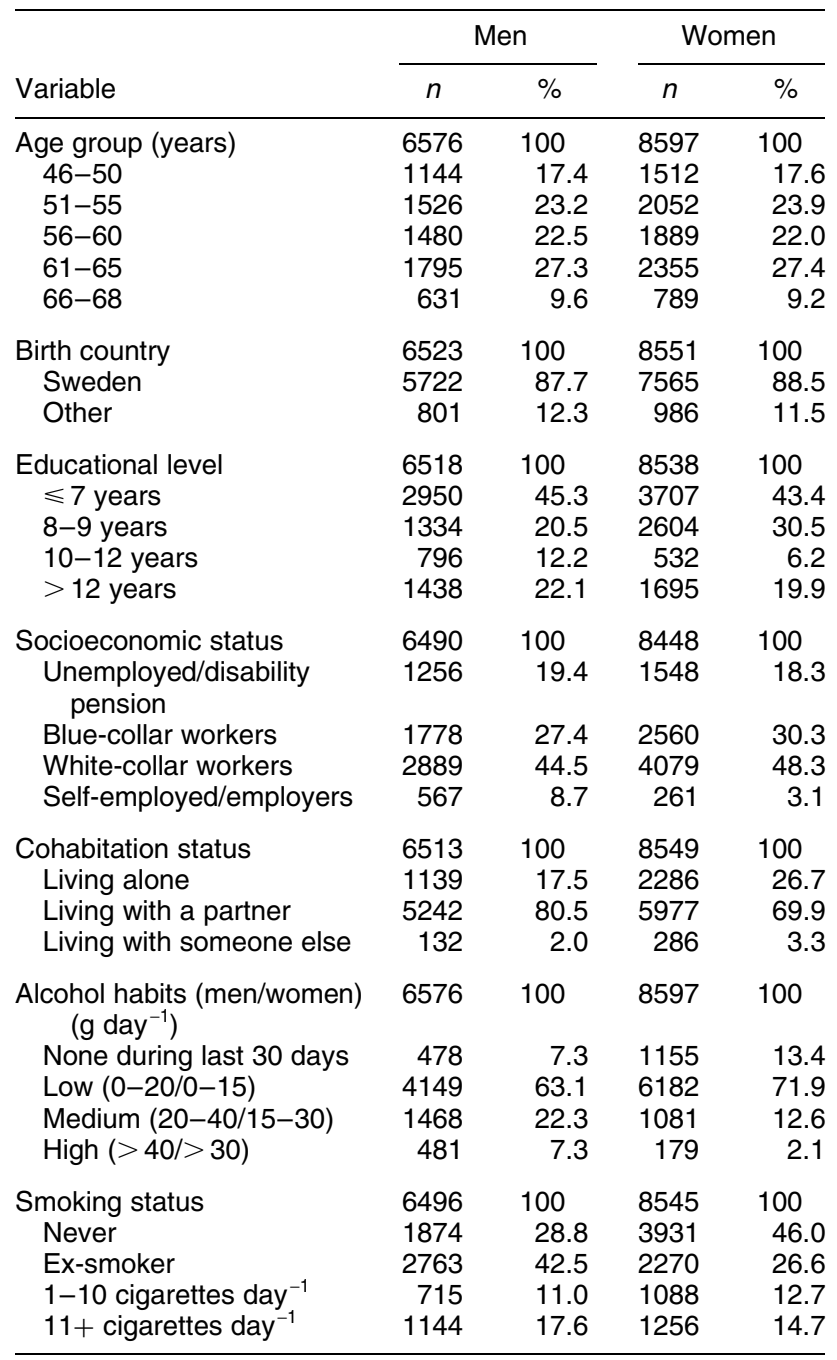

registration of cold beverages (including juices and alcoholic beverages) during seven consecutive days; and a 168-item food questionnaire (FQ) on regularly consumed foods (other than cooked) during the past year, such as snacks, cakes, fruits, hot beverages, yoghurt, breakfast cereals, all kinds of bread, butter and spreads, etc. In the FQ, usual portion sizes are estimated at home with the help of a book of photographs ( 48 photos). The FQ includes separate items for commonly consumed fruits in and out of season. Most of the vegetables consumed are recorded in the 7-day menu book. The usual portion sizes of the cooked meals recorded in the menu book were assessed at the second visit with the help of another, more extensive photograph book (180 photos). 'Fruits' comprised all citrus and non-citrus fruits and berries, including juices and dried fruits. The weights of dried fruits were corrected for their lower water content. 'Vegetables' comprised all cooked, dried and raw vegetables, tubers and roots, including juices and vegetables in casseroles, pizza and other mixed dishes. Potatoes are a staple food in 
Sweden and were therefore not included in the vegetable category.

The concurrent validity of the diet history method was previously tested against 18 days of weighed food records collected during 1 year as the reference ${ }^{6,8}$. The method yielded an overestimation of the absolute value for energy intake at group level of about $18 \%$ compared to the reference method ${ }^{6}$. The correlations between dietary factors estimated by the two methods were similar to or better than those found in other validation studies of similar methods, performed in other populations ${ }^{9-11}$. For example, two separate administrations of the diet history method $^{6}$ yielded average crude correlations between the diet history method and the reference method of 0.56, 0.69 and 0.54 for total energy, fruits and vegetables, respectively ${ }^{6,8}$. After 1 year, the corresponding reproducibility correlations were $0.71,0.82$ and $0.72^{7}$.

The amount of foods and nutrients consumed was calculated with the Kostsvar software (AIVO AB, Stockholm, Sweden) using the MDC Study nutrient database where the majority of nutrient information comes from the PC-KOST2-93 database (National Food Administration, Uppsala, Sweden).

\section{Questionnaire data}

A structured multiple choice questionnaire collected information on country of birth, level of education, cohabitation status, smoking habits, alcohol consumption, physical activity, etc.

Country of birth. Individuals born in other countries than Sweden were merged into a single category.

Level of education was divided into four categories. The educational level was converted to approximate number of years in the school system.

Cohabitation status. This variable was used in order to try to reduce the misclassification inherent in using civil status: persons living together without being married, etc. Subjects were divided into three categories: living alone, living with a partner or living with someone else. For men, the 'someone else' category consisted of men who were living with a child (44\%), parent (11\%) or some other person $(45 \%)$. The corresponding figures for women were $77 \%, 3 \%$ and $20 \%$, respectively. The first 2900 subjects (19\%) used a questionnaire in which it was not possible to distinguish people living with a partner from people living with someone else. These people were all coded as living with a partner.

Based on questionnaire items on subjects' profession, socioeconomic status was determined according to the Nordic occupation classification system ${ }^{12}$. The subjects were categorized as either 'blue-collar worker', 'whitecollar worker' or 'self-employed/employer'. Additionally, this classification was combined with information from another questionnaire item, concerning subjects' current occupation. The alternatives were 'housewife', 'gainfully employed', 'pensioner', 'student' and 'unemployed'.
Unemployed subjects and subjects who were pensioners without having reached the normal Swedish pension age of 65 were merged into a fourth category of socioeconomic status, 'unemployed/disability pension'.

Subjects were divided into four categories of smoking status: current smokers (up to or more than 10 cigarettes $\left.\mathrm{day}^{-1}\right)$, ex-smokers and non-smokers.

The information on alcohol consumption was collapsed into a four-category variable. Alcohol intake was mainly assessed from the 7-day menu book registration. However, those subjects who reported zero consumption in the menu book, and who indicated in the questionnaire that they had not consumed any alcohol during the previous 30 days or previous year, were categorized as zero consumers. The other subjects were categorized according to an assumption of biological risk ${ }^{13}$. Category ranges were, for men and women, respectively, $<20 \mathrm{~g} /<15 \mathrm{~g}$ alcohol day $^{-1}$ (low), 20-40 g/15-30 $\mathrm{g} \mathrm{day}^{-1}$ (medium) and $>40 \mathrm{~g} /$ $>30$ g day $^{-1}$ (high).

Physical activity during leisure time was assessed by a list of 18 different activities in the questionnaire, adapted from the Minnesota Leisure Time Physical Activity Questionnaire $^{14}$. The subjects were asked to fill in how many minutes per week they on the average were spending on the activity mentioned during each of the four seasons. These figures were all multiplied by an activity-specific factor. A physical activity score was obtained by computing the sum of all activity products. Four categories of physical activity status were identified by the subjects' quartile ranking (men and women separately).

\section{Statistical methods and design}

The average daily consumption of fruits and vegetables (including juices) was estimated. The subjects were ranked and divided into quartile groups of fruit consumption and vegetable consumption. Mean intakes of total energy, total fat, ascorbic acid, vitamin E, dietary fibre, $\beta$-carotene and selenium were estimated. The percentages of total non-alcohol energy contributed by fat, protein and carbohydrates were calculated. The ratio between polyunsaturated and saturated fatty acids (P/S ratio) and the ratio between $\omega-6$ and $\omega-3$ fatty acids ( $\omega-6 /$ $\omega-3$ ratio) were also estimated. The correlations between the consumption of fruit and vegetables on the one hand, and the other dietary variables on the other, were examined with correlational analysis. These correlation coefficients were calculated from $\log _{\mathrm{e}}$-transformed values.

In order to identify the independent associations between fruit or vegetable consumption and other risk markers for cancer, we used the general linear model (GLM) procedure in SPSS for Windows 8.0 (SPSS Inc., Chicago, Illinois, USA) with either fruit or vegetable consumption as the dependent variables. The independent variables were age group, cohabitation status, country of birth, educational level, socioeconomic status, 
smoking status, alcohol habits and physical activity. The independent variables were entered into the model simultaneously, with adjustment for interviewer, season and year. The dependent variables were $\log _{\mathrm{e}}$-transformed before analysis. When testing the alcohol and physical activity variables for trend, the categorized data were used. A total of 187 men (2.8\%) and 247 women (2.9\%) were excluded from these analyses because of missing data in one or more variables. The results are given as adjusted geometric means of consumption. Adjusted mean differences between categories of cohabitation status, smoking status and alcohol habits were also tested in the GLM procedure, meaning that alcohol category was evaluated both as an ordinal and as a categorical variable.

The unadjusted mean consumption of fruit and vegetables in each subgroup was also calculated. Since these results were similar to the results of the multivariate analyses, only the latter are presented.

\section{Results}

\section{The participants}

As seen in Table 1, the socioeconomic and lifestyle factors were reasonably similarly distributed in men and women. However, more men than women were living with a partner, and more men than women had medium or high alcohol intakes. Further, more men than women had ever smoked, although the proportion of current smokers were similar.

\section{Fruit, vegetables and nutrient intakes}

The average daily consumption of fruit (including juices) was $231 \mathrm{~g}$ in men and $285 \mathrm{~g}$ in women (Table 2). The average daily vegetable consumption (including juices) was $182 \mathrm{~g}$ and $198 \mathrm{~g}$, respectively.

The Pearson correlation coefficients between fruit and vegetable consumption were 0.27 and 0.29 in men and women, respectively. As seen in Table 3, men and women showed similar patterns of correlations between fruit or vegetables and the selected nutrients, but correlations between antioxidant nutrient intakes and fruit and vegetables were stronger in women than in men. Further, even though the mean intake values were similar in men

Table 2 Daily consumption of fruit and vegetables (including juices) by men ( $n=6576)$ and women ( $n=8597)$, showing means, standard deviations and percentiles

\begin{tabular}{llllll}
\hline & & & \multicolumn{3}{c}{ Percentile } \\
\cline { 5 - 6 } & Mean & SD & 25th & 50th & 75th \\
\hline $\begin{array}{l}\text { Fruits }(\mathrm{g}) \\
\quad \text { Men }\end{array}$ & 231 & 165 & 115 & 195 & 310 \\
$\quad$ Women & 285 & 165 & 168 & 260 & 374 \\
$\quad \begin{array}{l}\text { Vegetables (g) } \\
\quad \text { Men }\end{array}$ & & & & & \\
$\quad$ Women & 182 & 104 & 111 & 163 & 232 \\
& 198 & 107 & 126 & 179 & 249 \\
\hline
\end{tabular}

Table 3 Daily consumption of selected nutrients by men $(n=6576)$ and women $(n=8597)$, showing means, standard deviations and correlations between fruit, vegetables and nutrients $(P<0.01$ unless marked otherwise)

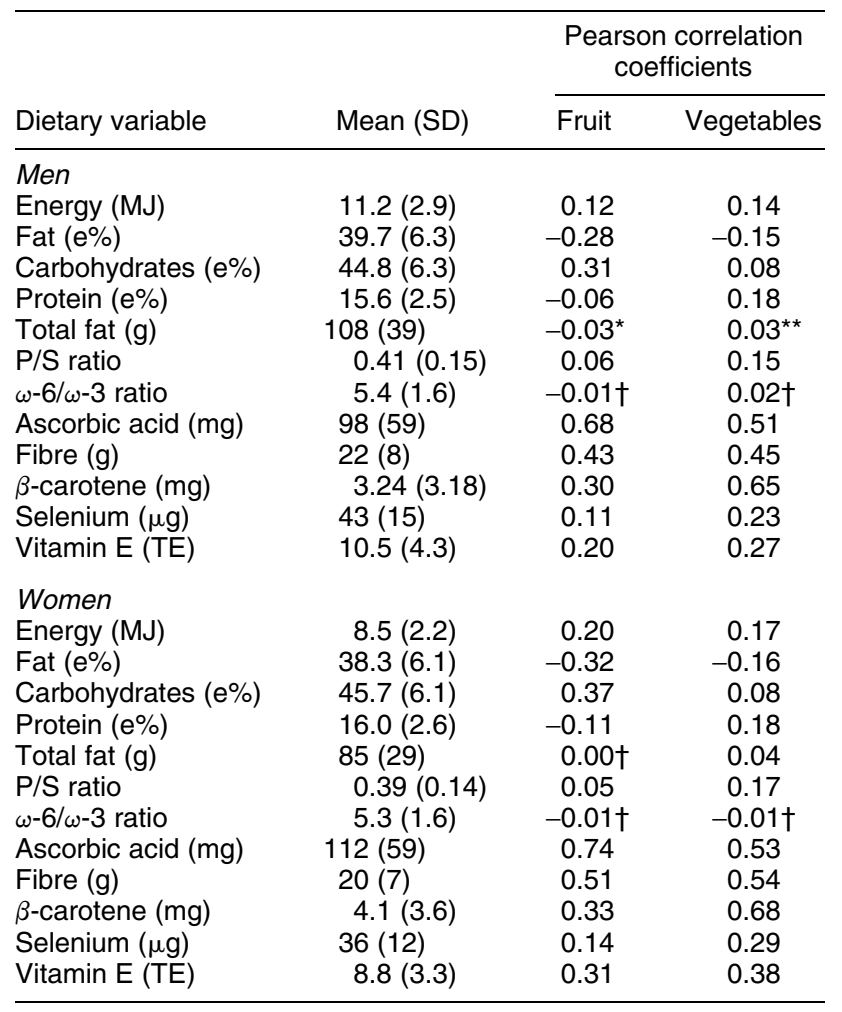

e\%, energy percentage; TE, tocopherol equivalents (1 TE corresponds to $1 \mathrm{mg}$ of $\mathrm{D}-\alpha$-tocopherol).

${ }^{*} P=0.03$.

${ }^{*} P=0.02$.

$\dagger P>0.05$.

and women, the energy and macronutrient intakes (expressed as energy percentages) were more highly correlated with fruit consumption in women than in men.

There were virtually no correlations between fruit or vegetables and fat intake, but high fruit consumption was associated with lower energy percentage from fat, more so than was vegetable consumption. The larger negative correlations with fat energy percentage were accompanied by higher positive correlations with carbohydrate energy percentage and with weakly negative associations with protein energy percentage. The ratio between polyunsaturated and saturated fatty acid intake was higher with higher vegetable consumption, but was only slightly higher with higher fruit consumption. There was no association with $\omega-6 / \omega-3$ fatty acid ratio.

\section{Fruit, vegetables and markers of cancer risk}

Adjusted fruit and vegetable consumption by demographic, socioeconomic and lifestyle factors is presented in Table 4.

High fruit consumption was associated with higher educational level, being born abroad and being physically active. Men living on their own had significantly lower fruit consumption than cohabiting men $(P<0.01)$. Heavier 
Table 4 Average daily consumption of fruit and vegetables using adjusted geometric means $^{*}$

\begin{tabular}{|c|c|c|c|c|}
\hline \multirow[b]{2}{*}{ Variable } & \multicolumn{2}{|c|}{ Fruit } & \multicolumn{2}{|c|}{ Vegetables } \\
\hline & Men & Women & Men & Women \\
\hline \multicolumn{5}{|l|}{ Age group (years) } \\
\hline $46-50$ & 181 & 214 & 170 & 181 \\
\hline $51-55$ & 183 & 220 & 169 & 179 \\
\hline $56-60$ & 185 & 230 & 163 & 174 \\
\hline $61-65$ & 185 & 225 & 158 & 168 \\
\hline $66-68$ & 189 & 229 & 142 & 157 \\
\hline$P$ for linear trend & 0.33 & 0.020 & $<0.001$ & $<0.001$ \\
\hline \multicolumn{5}{|l|}{ Birth country } \\
\hline Sweden & 166 & 216 & 141 & 163 \\
\hline Other & 205 & 230 & 176 & 183 \\
\hline$P$ for difference & $<0.001$ & 0.016 & $<0.001$ & $<0.001$ \\
\hline \multicolumn{5}{|l|}{ Educational level } \\
\hline$\leqslant 7$ years & 170 & 210 & 155 & 161 \\
\hline $8-9$ years & 191 & 222 & 167 & 176 \\
\hline $10-12$ years & 193 & 234 & 167 & 179 \\
\hline$>12$ years & 204 & 251 & 170 & 195 \\
\hline$P$ for linear trend & $<0.001$ & 0.001 & $<0.001$ & $<0.001$ \\
\hline \multicolumn{5}{|l|}{ Socioeconomic status } \\
\hline $\begin{array}{l}\text { Unemployed/disability } \\
\text { pension }\end{array}$ & 175 & 221 & 160 & 171 \\
\hline Blue-collar workers & 190 & 229 & 164 & 171 \\
\hline White-collar workers & 188 & 225 & 167 & 173 \\
\hline Self-employed/employers & 185 & 217 & 157 & 176 \\
\hline$P$ for difference & 0.13 & 0.45 & 0.040 & 0.73 \\
\hline \multicolumn{5}{|l|}{ Cohabitation status } \\
\hline Living alone & 161 & 230 & 154 & 173 \\
\hline Living with a partner & 184 & 226 & 167 & 177 \\
\hline Living with someone else & 211 & 213 & 166 & 168 \\
\hline$P$ for difference & $<0.001$ & 0.21 & $<0.001$ & 0.08 \\
\hline \multicolumn{5}{|l|}{$\begin{array}{l}\text { Alcohol habits (men/women) } \\
\left(\mathrm{g} \text { day }^{-1}\right)\end{array}$} \\
\hline None during last 30 days & 173 & 214 & 144 & 157 \\
\hline Low $(0-20 / 0-15)$ & 198 & 228 & 161 & 175 \\
\hline Medium (20-40/15-30) & 170 & 220 & 169 & 182 \\
\hline High $(>40 />30)$ & 152 & 191 & 174 & 170 \\
\hline$P$ for linear trend & $<0.001$ & 0.48 & $<0.001$ & $<0.001$ \\
\hline \multicolumn{5}{|l|}{ Smoker? } \\
\hline Never & 223 & 258 & 172 & 182 \\
\hline Ex-smokers & 200 & 240 & 172 & 186 \\
\hline $1-10$ cigarettes day $^{-1}$ & 183 & 222 & 160 & 167 \\
\hline $11+$ cigarettes day ${ }^{-1}$ & 142 & 181 & 145 & 157 \\
\hline$P$ for difference & $<0.001$ & $<0.001$ & $<0.001$ & $<0.001$ \\
\hline \multicolumn{5}{|l|}{ Physical activity, quartiles } \\
\hline 1st (lowest) & 148 & 185 & 144 & 153 \\
\hline $2 n d$ & 182 & 221 & 161 & 172 \\
\hline $3 r d$ & 199 & 237 & 167 & 181 \\
\hline 4th (highest) & 216 & 256 & 179 & 188 \\
\hline$P$ for linear trend & $<0.001$ & $<0.001$ & $<0.001$ & $<0.001$ \\
\hline
\end{tabular}

${ }^{*}$ All listed variables are adjusted for each other, for season and year of participation, and for interviewer.

smokers $\left(>10\right.$ cigarettes day ${ }^{-1}$ ) of both genders consumed considerably less fruit than all other smoker categories, with never-smokers having the highest consumption $(P<$ 0.001). High alcohol intake was also associated with low fruit consumption in both men and women. However, there was no significant trend across all four alcohol consumption groups in women. Indeed, when testing for non-linear differences between the categories, it was seen that the associations between alcohol category and fruit consumption appeared to be invertedly J-shaped in both genders (Fig. 1). This was most evident in men, where the low alcohol consumers consumed significantly more fruit than men in the three other categories $(P<0.001)$.

Similarly to fruit consumption, high vegetable consumption was associated with a longer education, being born abroad and being physically active. Men living on 


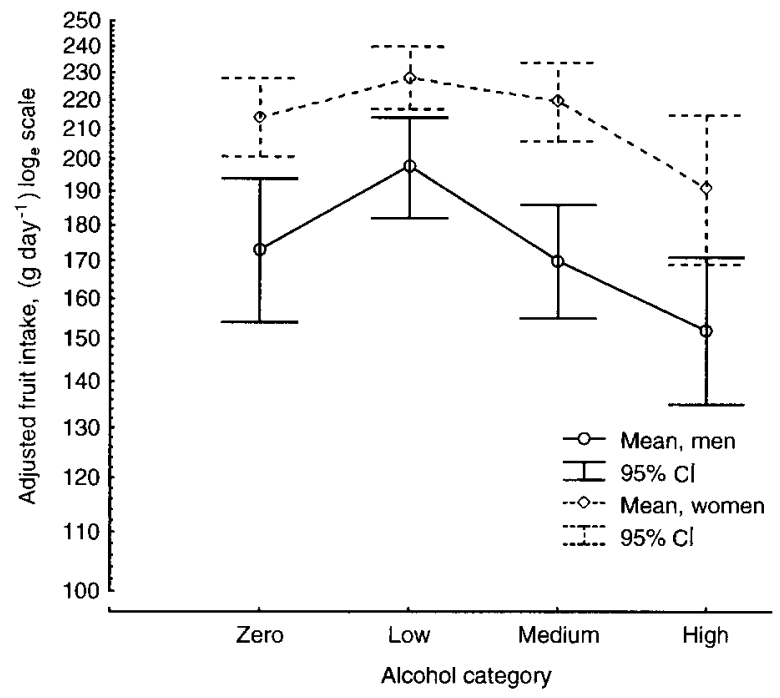

Fig. 1 Adjusted fruit intake by alcohol category for men and women

their own had significantly lower vegetable consumption than men living with a partner $(P<0.001)$. Non-smokers (never-smokers and ex-smokers) had significantly higher vegetable consumption than current smokers $(P<0.01)$. Further, light smokers had higher consumption than heavier smokers $(P<0.02)$. However, there was an inverse correlation with age, with a marked drop in vegetable consumption after 65 years of age. Further, as opposed to the negative association that was seen with fruit consumption, there was a significant positive association between alcohol intake categories and vegetable consumption in both genders (Fig. 2).

There were virtually no significant differences in fruit or vegetable consumption between socioeconomic groups after adjustment for the other factors.

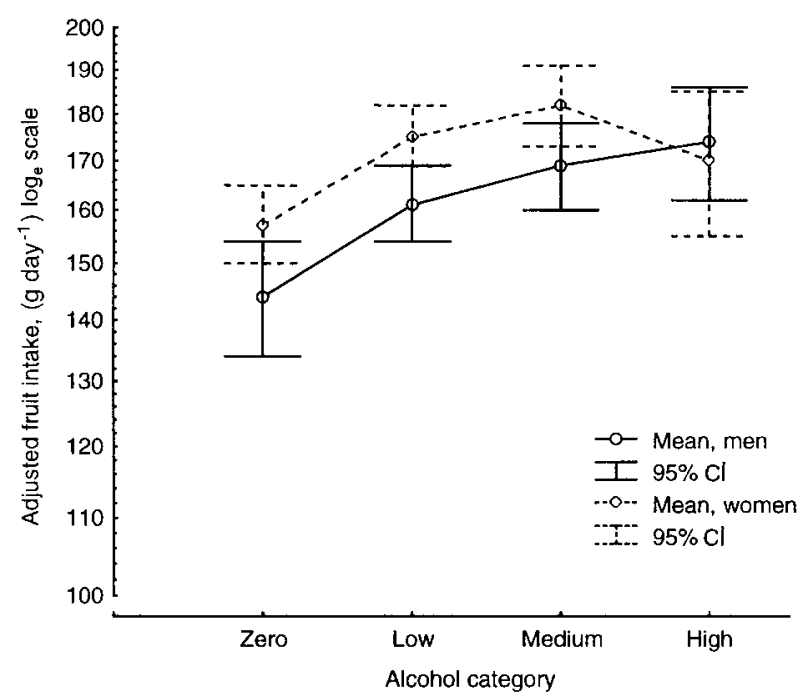

Fig. 2 Adjusted vegetable intake by alcohol category for men and

\section{Discussion}

Diets high in fruits and/or vegetables were generally associated with nutrient patterns in line with current recommendations. Women consumed more fruit and vegetables than men, and this difference remained after adjustment for all sociodemographic and lifestyle variables used in the study (data not shown). Low consumption of fruit and vegetables was significantly and consistently associated with smoking, low leisure time physical activity, low education and with being born in Sweden (men and women) and with living alone (men only). Persons over 65 had lower vegetable consumption than other persons. Alcohol intake was positively associated with vegetable consumption in both genders, while low alcohol consumers had higher fruit consumption than high alcohol consumers.

As noted in the methods section, almost a third of the subjects in the present study entered the MDC Study before receiving a letter of invitation. These subjects may have been more health conscious than other subjects, which might have introduced selection bias. Further, nonparticipation analyses of the MDC Study population have indicated that the participants may constitute a 'healthy cohort' (unpublished data). It may well be that study participants from population subgroups associated with low consumption (e.g. low educational level) may be more health conscious than non-participants belonging to the same subgroup. If so, a more representative sample may have resulted in even greater odds ratios than the present study has been able to show. The general direction of the results, however, would probably not have been affected, particularly since fruit and vegetables were not specifically mentioned in the invitation letters.

The data on energy intake and fat energy percentage in the present study are generally compatible with other Scandinavian large-scale surveys, as reviewed in Johansson et $a l .{ }^{15}$. The average fruit consumption in the present study, however, is rather high compared to similar studies. The validation study of the MDC diet assessment method indicated that fruit consumption was overestimated compared to the reference method (i.e. 18 days of weighed dietary records) to a larger extent than vegetable consumption $^{8}$, although it should be remembered that dietary records tend to underestimate the true intake ${ }^{16}$.

High alcohol consumption and smoking are generally considered to be causal risk factors for cancer. Low physical activity may also constitute a risk factor ${ }^{17}$. These lifestyle habits tend to associate with each other in a 'healthy/unhealthy behaviour pattern'. These patterns are often, on a group level, associated with sociodemographic factors. The present study is not the first to suggest that dietary factors perhaps should be included in these patterns. For example, Serdula et al. ${ }^{18}$ examined 22000 Americans and found lower consumption of fruit and vegetables among physically inactive subjects, current 
smokers who smoked at least 10 cigarettes day ${ }^{-1}$, and in subjects who consumed at least two alcoholic drinks daily. Women had higher consumption of fruit and vegetables than men. Further, Johansson and Frost Andersen, in a study in Norway ${ }^{19}$, found lower consumption of fruit and vegetables in male blue-collar workers, smoking women, sedentary men and women, and men and women who paid little or no attention to a recommended diet. They found no difference in educational status, however, and men had higher total consumption than women.

A number of other studies have examined the relations between unfavourable dietary habits, defined as low fruit/ vegetable consumption and/or high fat intake, and one, or only a few risk factors of disease. Smokers in different parts of the world have been reported to have such dietary habits ${ }^{20}$. Other examined risk markers or causal risk factors include educational level ${ }^{21,22}$, social class $^{22-24}$ and physical activity ${ }^{18,25}$, which generally tend to be positively associated with recommended dietary habits. Alcohol intakes have in such studies been negatively correlated with antioxidant nutrients and positively correlated to fat intake measures ${ }^{25}$. Of particular interest in relation to our study is the Swedish National Household Budget Survey ${ }^{26}$, which found that women had a higher intake of $\beta$-carotene and ascorbic acid per unit of energy intake than men. Further, subjects with low education and smokers had lower consumption of fruit and vegetables than others, and often higher fat intakes as well. This study included subjects from 18 years of age and up. Our study mostly agrees with this collected evidence.

It is noteworthy that the differences in fruit and vegetable consumption between the categories of smokers in our study are very large, even though we have adjusted for several potentially confounding factors at the same time. According to our data, smokers, who are exposed to large amounts of toxic and carcinogenic substances and reactants through their smoking, definitely tend to have dietary habits that may decrease their protection from pathogenic processes. As mentioned above, similar findings are not uncommon ${ }^{20}$; possible explanations are briefly reviewed in Serdula et al. ${ }^{18}$.

The positive association between consumption of vegetables and alcohol intake, and the resulting low consumption in alcohol abstainers, was not caused by a low overall energy intake, since the result was unchanged by energy adjustment (data not shown). This result, which does not fit the standard 'health behaviour pattern', may instead be indicative of a dietary pattern characterized by low consumption of alcoholic beverages and vegetables, but high in sugar- and fat-containing foods, such as cakes, pastries, etc. Such observations have been made in a study of food patterns in another subsample of the MDC Study ${ }^{27}$.

Another possibility is related to the 'French paradox', i.e. an association between high wine consumption and low incidence of cardiovascular disease ${ }^{28,29}$. A recent study from Copenhagen by Tjønneland et al. showed a positive association between the consumption of wine and vegetables, suggesting that the implied health benefits of wine may be partly confounded by vegetable consumption $^{30}$. Copenhagen is geographically and culturally close to Malmö, which suggests that a similar association might be hidden in our data. We did not examine the different alcohol sources separately, but the comparatively higher vegetable consumption among light-moderate alcohol consumers may indicate such a relation.

The association between fruit and alcohol consumption is provokingly similar to a mirror-image of the wellknown J-shaped association between alcohol intake and cardiovascular morbidity and mortality. This indicates that those with the lowest cardiovascular risk, i.e. lowmoderate alcohol consumers, may also be the ones with the highest fruit consumption. Since fruit consumption has been associated with lower risk of cardiovascular disease, this finding implies that the suggested health benefits of alcohol may be partly confounded by fruit consumption.

Fruits and vegetables have somewhat differing nutritional correlates. Fruit consumption was associated with lower energy percentage from fat to a much higher degree than was vegetable consumption. This may of course be explained by the higher energy content of fruits than vegetables, which means that energy from fat tends to be replaced by energy from the low-fat fruits, particularly in women. Further, vegetables may often be eaten with fatcontaining dressing. The differing nutrient patterns, and the fact that the associations between consumption of fruit and vegetables were moderate, imply that consumption of fruits and vegetables are two different behaviours vegetables are probably mostly eaten as a part of regular meals, while fruits are mainly eaten between meals. This, incidentally, may also explain the lower vegetable consumption in subjects over 65 , the normal retirement age in Sweden, since retirement may bring about changes in the number of cooked meals eaten per week.

The kind of variables used in this study are far from perfect for predicting consumption levels in the subjects. The adjusted $R^{2}$ values for the multivariate models ranged from $6.6 \%$ to $9.7 \%$, which are similar to those found in other studies ${ }^{31-33}$. Clearly, other factors need to be taken into account if we want to increase our understanding of factors that determine fruit and vegetable consumption. Recently, adverse dietary habits, defined as either low consumption of fruit and vegetables or as high fat intake, have been associated with food preferences ${ }^{34-36}$, nonacceptance of a relation between diet and health, household income and concern about one's appearance ${ }^{34}$. Stress in general ${ }^{37}$, stress at work ${ }^{38}$ and the tendency to use certain foods as a coping strategy ${ }^{37}$ have also been implicated. This list also serves to remind us that work on several levels is necessary if fruit and vegetable promotion at a population level is to be a success ${ }^{34,39}$. 


\section{Conclusions}

This study indicates that several established risk markers and risk factors of cancer are also independent markers of exposure to low levels of fruit and/or vegetables. These findings support several previous studies, implying a possibility that part of the commonly found associations between these risk markers or risk factors and cancer, could be mediated through low fruit/vegetable consumption.

\section{Acknowledgements}

This study was supported by grants from the Swedish Cancer Society (2684-B93-05XAA) and the Swedish Medical Research Council (B93-39X-09534-03C). The authors wish to thank the participants and staff of the Malmö Diet and Cancer Study. The authors also wish to thank Sivert Carlsson, Bo Gullberg, Petra Lahmann and Ghassan Salameh for assistance and advice.

\section{References}

1 Sies $\mathrm{H}$, Stahl W. Vitamins $\mathrm{E}$ and $\mathrm{C}, \beta$-carotene, and other carotenoids as antioxidants. Am. J. Clin. Nutr. 1995; 62 (Suppl.): S1315-21.

2 Steinmetz KA, Potter JD. Vegetables, fruit, and cancer prevention: a review. J. Am. Diet. Assoc. 1996; 96: 102739.

3 Steinmetz KA, Potter JD. Vegetables, fruit, and cancer. II. Mechanisms. Cancer Causes Control 1991; 2: 427-42.

4 Johnson IT, Williamson G, Musk SRR. Anticarcinogenic factors in plant foods: a new class of nutrients? Nutr. Res. Rev. 1994; 7: 175-204.

5 Berglund G, Elmståhl S, Janzon L, Larsson SA. The Malmö Diet and Cancer Study. Design and feasibility. J. Intern. Med. 1993; 232: 45-51.

6 Riboli E, Elmståhl S, Saracci R, Gullberg B, Lindgärde F. The Malmö Food Study: validity of two dietary assessment methods for measuring nutrient intake. Int. J. Epidemiol. 1997; 26 (Suppl. 1): S161-73.

7 Elmståhl S, Gullberg B, Riboli E, Saracci R, Lindgärde F. The reproducibility of a novel diet history method and an extensive food frequency questionnaire. The Malmö Food Study. Eur. J. Clin. Nutr. 1996; 50: 134-42.

8 Elmståhl S, Riboli E, Lindgärde F, Gullberg B, Saracci R. The Malmö Food Study. The relative validity of a modified diet history method and an extensive food frequency questionnaire for measuring food intake. Eur.J. Clin. Nutr. 1996; 50: $143-51$.

9 Willett WC, Sampson L, Stampfer MJ, et al. Reproducibility and validity of a semiquantitative food frequency questionnaire. Am. J. Epidemiol. 1985; 122: 51-65.

10 Block G, Woods M, Potosky A, Clifford C. Validation of a self-administered diet history questionnaire using multiple diet records. J. Clin. Epidemiol. 1990; 43: 1327-35.

11 Pietinen P, Hartman AM, Haapa E, et al. Reproducibility and validity of dietary assessment instruments. I. A selfadministered food use questionnaire with a portion size picture booklet. Am. J. Epidemiol. 1988; 128: 655-66.

12 Statistics Sweden. Occupations in Population and Housing Census 1985 (FoB 85) according to Nordic Standard Occupational Classification (Nordisk yrkesklassificering,
NYK) and Swedish Socio-economic Classification (Socioekonomisk indelning, SEI) [in Swedish]. Reports on Statistical Co-ordination 1989:5. Stockholm: Statistics Sweden, 1989.

13 Royal College of Psychiatrists. Alcohol: Our Favourite Drug. London: Tavistock, 1986

14 Taylor HL, Jacobs Jr DR, Schucker B, Knudsen J, Leon AS Debacker G. A questionnaire for the assessment of leisure time physical activity. J. Chron. Dis. 1978; 31: 741-55.

15 Johansson L, Solvoll K, Aa Bjørneboe G-E, Drevon CA. Dietary habits among Norwegian men and women. Scand.J. Nutr. 1997; 41: 63-70.

16 Margetts BM, Nelson M, eds. Design Concepts in Nutritional Epidemiology, 2nd edn. Oxford: Oxford University Press, 1997.

17 McTiernan A, Ulrich C, Slate S, Potter J. Physical activity and cancer etiology: associations and mechanisms. Cancer Causes Control 1998; 9: 487-509.

18 Serdula MK, Byers T, Mokdad AH, Simoes E, Mendlein JM, Coates RJ. The association between fruit and vegetable intake and chronic disease risk factors. Epidemiology 1996; 7: 161-65.

19 Johansson L, Frost Andersen L. Who eats 5 A Day?: intake of fruits and vegetables among Norwegians in relation to gender and lifestyle. J. Am. Diet. Assoc. 1998; 98: 689-91.

20 Midgette AS, Baron JA, Rohan TE. Do cigarette smokers have diets that increase their risks of coronary heart disease and cancer? Am. J. Epidemiol. 1993; 137: 521-9.

21 Kushi LH, Folsom AR, Jacobs Jr DR, Luepker RV, Elmer PJ, Blackburn H. Educational attainment and nutrient consumption patterns: the Minnesota Heart Study. J. Am. Diet. Assoc. 1988; 88: 1230-6.

22 Braddon FEM, Wadsworth MEJ, Davies JMC, Cripps HA Social and regional differences in food and alcohol consumption and their measurement in a national birth cohort. J. Epidemiol. Community Health 1988; 42: 341-9.

23 Aro S, Räsänen L, Telama R. Social class and changes in health-related habits in Finland in 1973-1983. Scand. J. Soc. Med. 1986; 14: 39-47.

24 Bolton-Smith C, Smith WCS, Woodward M, Tunstall-Pedoe $\mathrm{H}$. Nutrient intakes of different social-class groups: results from the Scottish Heart Health Study (SHHS). Br. J. Nutr. 1991; 65: 321-35.

25 La Vecchia C, Negri E, Franceschi S, Parazzini F, Decarli A. Differences in dietary intake with smoking, alcohol, and education. Nutr. Cancer 1992; 17: 297-304.

26 Becker W. Food Habits and Nutrient Intake in Sweden 1989 (Befolkningens kostvanor och näringsintag i Sverige 1989. Metod- och resultatanalys) [in Swedish, with a summary in English]. Uppsala: Statens Livsmedelsverk, 1994.

27 Wirfält E, Mattisson I, Gullberg B, Berglund G. Food patterns defined by cluster analysis and their utility as dietary exposure variables. Public Health Nutr. 2000 (in press).

28 Klatsky AL, Armstrong MA. Alcoholic beverage choice and risk of coronary artery disease mortality: do red wine drinkers fare best? Am. J. Cardiol. 1993; 71: 467-9.

29 Grønbæk M, Deis A, Sørensen TIA, Becker U, Schnohr P, Jensen G. Mortality associated with moderate intakes of wine, beer, or spirits. BMJ 1995; 310: 1165-9.

30 Tjønneland A, Grønbæk M, Stripp C, Overvad K. Wine intake and diet in a random sample of 48763 Danish men and women. Am. J. Clin. Nutr. 1999; 69: 49-54.

31 Harnack L, Block G, Subar AF, Lane S, Brand R. Association of cancer prevention-related nutrition knowledge, beliefs, and attitudes to cancer prevention dietary behavior. J. Am. Diet. Assoc. 1997; 97: 957-65.

32 Krebs-Smith SM, Heimendinger J, Patterson $\mathrm{BH}$, et al. Psychosocial factors associated with fruit and vegetable consumption. Am. J. Health Prom. 1995; 10: 98-104.

33 Havas S, Treiman K, Langenberg $\mathrm{P}$, et al. Factors associated with fruit and vegetable consumption among women participating in WIC. J. Am. Diet. Assoc. 1998; 98: 1141-8. 
34 Turrell G. Determinants of healthy food choice in a population-based sample. Am. J. Health Behav. 1998; 22: 342-57.

35 Caltabiano ML, Shellshear J. Palatability versus healthiness as determinants of food preferences in young adults: a comparison of nomothetic and idiographic analytic approaches. Aust. NZ J. Public Health 1998; 22: 547-551.

36 Glanz K, Basil M, Maibach E, Goldberg J, Snyder D. Why Americans eat what they do: taste, nutrition, cost, convenience, and weight control concerns as influences on food consumption. J. Am. Diet. Assoc. 1998; 98: 1118-26.
37 Steptoe A, Lipsey Z, Wardle J. Stress, hassles and variations in alcohol consumption, food choice and physical exercise: a diary study. Br. J. Health Psychol. 1998; 3 (Part 1): 51-63.

38 Hellerstedt WL, Jeffery RW. The association of job strain and health behaviours in men and women. Int. J. Epidemiol. 1997; 26: 575-83.

39 Povey R, Conner M, Sparks P, James R, Shepherd R. Interpretations of healthy and unhealthy eating, and implications for dietary change. Health Educ. Res. 1998; 13: $171-83$. 